\title{
Sustainable Business and Consumption Trends 2019
}

Please cite this article as:

Tăchiciu L., 2019. Sustainable Business and Consumption Trends 2019. Amfiteatru

Economic, 21(Special Issue No. 13), pp. 740-742.

DOI: $10.24818 / \mathrm{EA} / 2019 / \mathrm{S} 13 / 740$

Today, change is the New Normal. Change is driven by fast and ever accelerating advances in science and technology. Yesterday's fictions as artificial intelligence, internet of things, self-driving cars, smart houses, 3D printing, automated warehouses, etc. are becoming realities and are already or will soon be familiar means in people's everyday life. Progress in nanotechnology, biotechnology, photonics, advanced materials and advanced manufacturing, joining digitalization and supporting each other, give rise to new behaviors and aspirations and shape new economic and social structures and relations. The need for a development model that is better adapted to the new conditions and which offer more security for the future, is increasingly felt. Such a model of sustainable development must reconcile economic growth with environmental protection, promote fairer social relations and be more resilient to crises at local, regional and global levels. There is an urgent need to slow down global warming, stop wasting resources, reduce development gaps and prevent the emergence of new gaps as a result of demographic, technological, economic, political and social changes.

It is questionable to which extent the current governance systems correspond to the desiderates listed above, especially since the progress being made are still modest compared to the ambitions set out rhetorically.

In this context, the researchers strive to detect as early as possible the signs of changes likely to have a lasting impact on the economy and society, to foreshadow the consequences of current actions and the meaning of future developments. A construction site of this nature is also the series of international conferences promoted by the Association for Innovation and Quality in Sustainable Business BASIQ under the generic title of "New Trends in Sustainable Business and Consumption".

Amfiteatru Economic Journal has included in this special issue some of the most interesting contributions initially presented at the 2019 edition of the BASIQ conference series, hosted by the University of Bari Aldo Moro between May 30 and June 1, 2019.

Miron, Șeuleanu Cojocariu and Benchea point out the importance of a so-called quaternary sector made up of intensely cognitive and creative activities in the 
contemporary developed economies. They believe that a new paradigm of economic development is needed, along with appropriate measurement tools, analytical frameworks and decision-making methods to meet the challenges of an economy where the quaternary sector is becoming prevalent. The authors identify a certain lagging behind of the European Union in terms of ensuring external competitiveness, considering that this is partly due to maintaining the commitment to cohesion at the expense of better consolidation and exploitation of the poles of excellence.

Along the lines of highlighting the importance of activities based on the intensive use of knowledge and creativity, there is also the work of Nițescu, Murgu and Căpriță, which highlights the important role of researchers and R\&D in ensuring the competitiveness of the economy and promoting sustainable development.

The papers referred to in the preceding paragraph also indicate the imperative of transforming the education system from one focused on knowledge acquisition to one focused on developing critical thinking, interest in knowledge and lifelong learning skills. The same idea is also supported by the results of the research conducted by Gotesman Bercovici and Bercovici on the labor market in Israel regarding the changes induced by the fourth industrial revolution. Organizations must face the challenges by implementing solutions to promote lifelong learning, up-skilling and re-skilling, on the one hand, and by adapting management to different age categories, on the other. Employees, in turn, must "learn how to learn", adapting to increasing professional mobility requirements.

Mobility, in all its aspects, is an important feature of contemporary transformations in society and economy. The work on the role of international mobility of young Europeans in promoting entrepreneurship brings new evidence in this regard. Its authors, Roman and Paraschiv, using a comprehensive database and rigorous analytical tools, show that the propensity to start a business on their own is twice as high among young people who have traveled abroad for at least two weeks, compared with those who have not traveled.

Supporting the need for adapting the management of organizations in relation to the objectives of sustainable development, Muradin and Foltynowicz explore the need and feasibility of an international standard on the circular economy, in particular through the development and unitary use of new performance indicators to measure the degree of "circularity".

One of the most intriguing contemporary developments relying on technology is the rise of the cryptocurrency market, which challenge the established monetary market pattern. Rana, Giungato, Tarabella and Tricase investigate the controversial issue of energy consumption by blockchain applications and find no limitation to the expansion of such a technology from a sustainability perspective. Moreover, the authors appreciate that blockchain technology has important advantages in reducing bureaucracy and strengthening democracy, recommending its use for other purposes, as well. 
The reduction of energy consumption can be achieved without affecting the living or working conditions of people. Moreover, those who apply energy efficiency solutions can achieve significant financial savings. The case of the University of Bari Aldo Moro presented by Amicarelli, Lagioia, Bux and Gallucci is a case of exemplary good practice that can inspire the decisions and the action of other administrators of non-residential buildings.

Consumers, through their preferences and purchasing and consumption behavior, play a central role in transforming economic structures. This results from two articles included in this special issue, even though the approaches are different, and the conclusions seem to be contradictory. Studying the market of fast moving consumer goods (FMCG), Stanciu, Vîrlănuță, Vochin, Ionescu and Antohi, they find a high degree of concentration, but also a high level of competition that determines the companies to respond to the preferences of the buyers for modern forms of sale and a character more pronounced domestic and ecological of the offered products. On the other hand, Pagliacci, Manolică, Roman and Boldureanu find that the preference for green products is more pronounced among young women and families with young children, but also that the respondents included in the surveyed sample show no confidence in the authenticity and quality of the products distributed through the modern commercial chains.

We hope that readers will find in this special issue interesting and useful information, as well as the motivation of further investigation of some of the issues discussed here.

\section{Laurențiu Tăchiciu, Managing editor}

